\title{
A ESCOLA COMO ESPAÇO DE INTERDISCIPLINARIDADE E REFLEXÃO - UM ESTUDO SOBRE A PRIMEIRA EDIÇÃO DO FÓRUM DE HUMANIDADES PROMOVIDO PELO COLÉGIO UNIVAP - UNIDADE AQUARIUS, SJC-SP
}

Thifani de Carvalho'

Nádia Cristina Portes ${ }^{2}$

Viviana Mendes Lima ${ }^{3}$

Jobair de Assis Rangel ${ }^{4}$

Resumo: Este trabalho consiste em apresentar os resultados acerca das experiências educacionais, no que tange a interdisciplinaridade, na área de ciências humanas e suas tecnologias a partir da temática proposta pela UNESCO (Organização das Nações Unidas para a Educação, Ciência e Cultura), de acordo com a proposta "2016 Ano Internacional do Entendimento Global”. Ante a necessidade de refletir e debater os principais problemas globais que afetam o desenvolvimento da sociedade como um todo, o fórum propôs a todos uma reflexão em torno dos seguintes problemas: crise dos refugiados, problemas ambientais, relações sociais e a globalização. A metodologia adotada teve base em pesquisas de artigos acadêmicos, livros didáticos e sites de organizações governamentais idôneas que foram indispensáveis na construção deste artigo. Considera-se relevante abordar temas globais na formação dos alunos do ensino médio, preparando-os para uma postura firme ao abordar estas temáticas, assim como tantas outras.

Palavras-chave: Educação; Entendimento global.

\footnotetext{
1 Colégio Univap - Aquarius/Ensino Médio, Brasil. E-mail: thifanicarvalho3@gmail.com.

2 Colégio Univap - Aquarius/Ensino Médio, Brasil. E-mail: nadiacportes@gmail.com.

3 Colégio Univap - Aquarius/Docente Ensino Médio, Brasil. E-mail: geomendes@usp.br.

${ }^{4}$ Colégio Univap - Aquarius/Docente Ensino Médio, Brasil. E-mail: jobairrangel@terra.com.br.
} 